\title{
Logistics Software from a Logistics Management and Management Information Systems (MIS) Perspective
}

\author{
Hermann Gruenwald \\ Burapha University International College, Bangsaen, Thailand \\ GruenwaldH@yahoo.com
}

\begin{abstract}
The logistics profession has undergone severe changes over the last few decades, replacing muscle power with brain power. The virtual aspect of logistics has become equally important to the physical realm of transportation and warehousing. Supply Chain Management (SCM) deals with getting the right stuff to the right people at the right time in the right amount. To accomplish this task there are a number of more or less integrated logistics software application. Demand forecasting models based on historical data from data marts and data warehouses with built in seasonality and pricing models. Load planning software to appropriately palletize, containerize and load trucks and vessels. Route planning software with real time traffic and weather updates to reduce time and fuel costs. Electronic documents to accompany the shipment from purchase order, letter of credit to customs clearing and back-haul charges. Logistics software has many aspects and may be viewed differently from a software developer and user perspective. This study compares the perception of logistics software by management information systems (MIS) and logistics management students (Logistics) in Thailand. Some of the aspects include: user friendliness, ease of use, features and benefits, technical limitations.
\end{abstract}

Keywords: Management Information Systems (MIS), Supply Chain Management (SCM) Software, Transportation \& Warehouse Management, Logistics Management, Logistics Software

\section{Introduction}

Logistics has changed over the years and moved from transportation and warehousing to integrated logistics solutions which cover the entire life cycle of the supply chain and start with demand forecast and close with reverse logistics and recycling of the good created on the farm or factory which were received by the personal or industrial end users. Logistics as a profession moved from load dock workers and teamsters to managers. Where once physical labor dominated today the key factor often more critical than the movement of the goods is the electronic information. Having said that it is clear that today's logistics professional have to have a keen awareness of logistics information system can do and how to handle them. These information systems have to be created by someone. Many years ago the logistics software was created in house by some computer savvy logistics employees in the company who had a basic understanding of spreadsheets, databases and computer programming. The programming language of choice used to be basic and visual basic as it is a skill set that is readily available and often already taught at the high school level. This started with simple macros which were added to the spreadsheets or even word documents. Spreadsheets clearly were the preferred approach to collecting and storing information. Spreadsheets are single user but are difficult to manage when many users simultaneously input and update information. Databases were often created on the Microsoft platform using dbase, which is not a truly object oriented database. Multiple users could access and enter data simultaneously. The computers were initially connected through a sneaker network carrying floppy disks from desktop to desktop and later through local network cables that often ran on the office floor before finding their way in the suspended ceiling. The internet changed all that and local area networks both hard wired and wireless connected the office computers to each other's and the rest of the world. This also allowed for web-enabled databases and applications which could be accessed from around the world on local servers. Wireless also allows the use of a smaller foot print in the form of hand-held applications as laptops, tablets, and smart phones. Logistics Software can be broadly divided into the following categories:

- Supply Chain Management (SCM) deals with getting the right stuff to the right people at the right time in the right quantity 
- Enterprise Resource Planning (ERP) deals with integrating the enterprise as a whole this applies in particular to third party logistics providers 3PL

- Supplier Relationship Management (SRM) this software tries to accurately forecast the demand thereby reducing transportation and holding costs

- Transportation Management Systems (TMS) what equipment and staff to use to ship it the fastest way and most cost efficient, selecting the right mode of transportation (land, water, air) loading the box, the crate, the container and the vessel the most efficient way as a subset it includes Global Positioning System (GPS)

- Warehouse Management Systems (WMS) how to manage warehouses of various forms and shapes with various special functions such as climate controlled warehouses, automated warehouses, as well as container yards, distribution centers and cross docking facilities.

- Electronic Data Interchange (EDI) introduced in the 1960s allows real-time data exchange and was the forerunner of the internet and is heavily used in logistics even so it is not an exclusive logistics application

- Radio Frequency Identification (RFID) is replacing barcodes and allows the tracking of individual items, cartons, pallets, containers and movement vehicles

\section{Literature Review}

In the literature review we looked at three main bodies of literature: management information system literature, logistics literature and logistics software literature. Logistics developed over centuries from the movement and warehousing to integrated logistics applications. The global supply chain requires an integrated logistics management solution, which is technology enabled (Arnold, 2008). The scientific logistics software literature is relative limited. Even the trade magazines for computer software and logistics have limited information when it comes to logistics software. The resources could be found on the vendors' websites, one has to be careful to distinguish between fact and hype of the software vendors. We also looked at the various categories of logistics software, Supply Chain Management (SCM), Enterprise Resource Planning (ERP), Supplier Relationship Management (SRM), Transportation Management Systems (TMS), Global Positioning System (GPS), Warehouse Management Systems (WMS), Electronic Data Interchange (EDI), Radio Frequency Identification (RFID) for applied and theoretical research (Baumgartner, 2001). The literature related to ERP and supply chain software (Gammelgaard \&Larson, 2001), was most fruitful both in terms of cases studies and limited theory basses (Anderson, 2003). There has been some finding that application software related to logistics applications lack the integration across the entire enterprise spectrum, the most integrated solution is provided by the German company SAP, but SAP for logistics applications is quite costly both from a licensing as well as implementation cost. The MIS literature deals with the issues of how individuals and corporations embrace technology and modify their business processes to best make use of the changing technology or adopt technology to fit their existing processes (Markus \& Robey, 1988). Besides the technology roadmap and technology integration a major issue in MIS the interaction of humans and technology (Alavi \& Carlson 1992). The technical issues are addressed in depth by electrical engineering and computer science, the mayor problem is not technology but the human factor. Computer systems implementations following industry best practices are always a change management issues. Most people naturally resist change to one level or another. MIS deals less with the actual programming and the hardware issues and more with the difficulties at stake integrating the enterprise, departments and the individual stakeholders. A stakeholder analysis also contributes not only to establish user requirements but also to make the users a part of the development and implementation process. There have been numerous studies related to MIS and change management but there are limited studies related to the use and implementation of logistics software in the logistics industry.

\section{Methodology}

This quantitative study surveyed undergraduate management information system (MIS) and logistics students in Thailand who studied in international programs. The survey was web-enabled and could be taken at the convenience of the students. The survey used the Moodle based e-learning system to administrate the survey. The survey used a five point likert scale. This research measured the perception of MIS and logistics students regarding logistics software and their first and limited impression of the software. Both student groups were introduced to logistics software in the 
respective course and received limited exposure to the software. Their impression comes mostly from the trade literature and the company websites. They also viewed the available demo videos and had a chance to test drive some of the software in the free software downloads through the vendor web sites. Screen shots of the software further contributed to the first impression in terms of user interface and user friendliness. The students were using the various software applications throughout the curriculum and were more and less familiar with the various types of applications. The percentage of male and female participants reflects the distribution in the MIS and logistics workforce. 35 female respondents and 22 male. The age distribution of the population was also representative of bachelor degree MIS and logistics students. Only $2 \%$ of the students were freshmen students age $18,16 \%$ of the students were freshmen age 19 , the majority of the students were second year students $32 \% 20$ years old and $37 \%$ of the students being age 21 . There were only $14 \%$ of the students who were 22 years old who may have entered college late or took this elective course out of sequence. For analysis purposes SPSS was used by the principal investigator (PI).

\section{Results}

When asked what logistics software information the respondents were familiar with, the respondents found the following logistics software applications as most useful based on previous experiences. The MIS and logistics students pretty much agreed on the importance of the various applications only that the MIS students in general rate the logistics specific applications lower as the more well known applications like supply chain management, even so these differences are not significant. The more significant differences are in the areas such as EDI and RFID, which are more technical applications and probably more well know among MIS students than among logistics students. Supplier Relationship Management software was not recognized either by MIS nor logistics students, maybe because it was not covered in depth in the various courses. Warehouse management surprisingly was the most popular application, and even among logistics students RFID was recognized, while transportation planning was really undervalued by the participants.

Table 1: Most useful logistics software applications

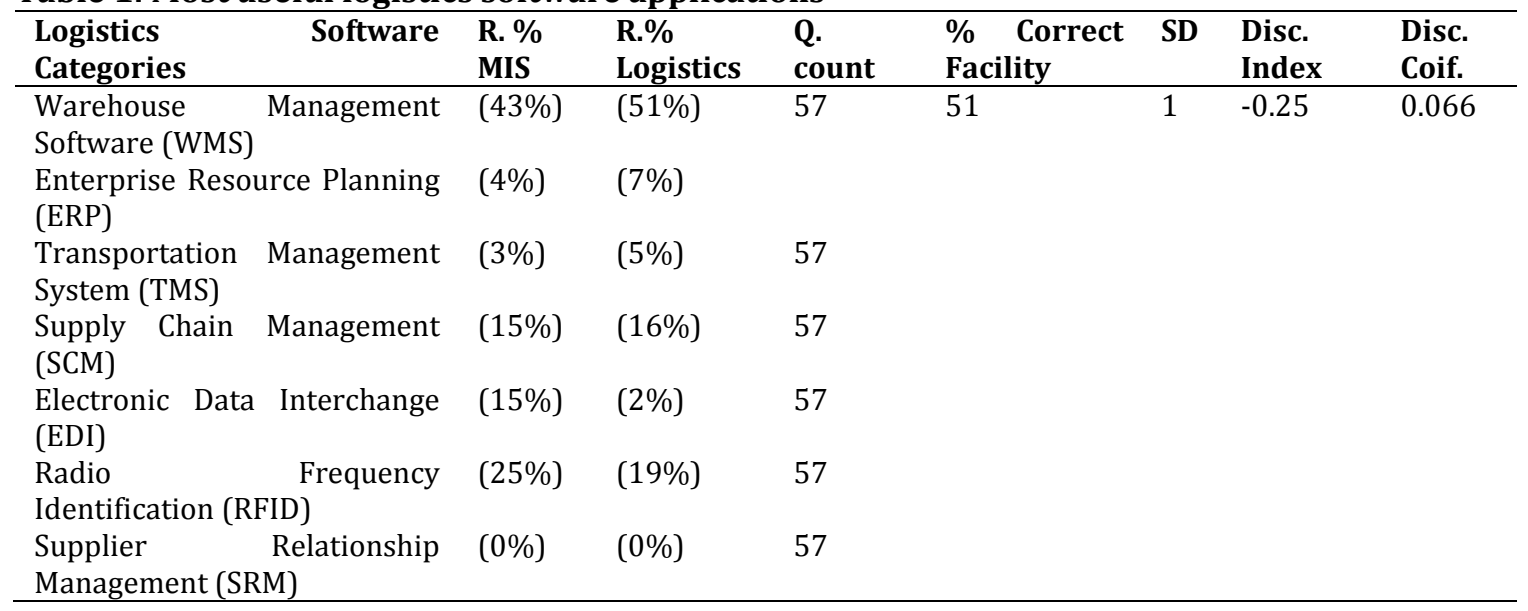

If the users were asked if the like to use logistics software versus doing the work manually, the overwhelming number participants either very much liked (42\%) or liked (35\%) to use various forms of logistics software.

Table 2: Like to use logistics software

\begin{tabular}{lllllllll}
\hline Logistics Software Usage & $\begin{array}{l}\text { R. } \\
\text { Counts }\end{array}$ & R.\% & $\begin{array}{l}\text { Q. } \\
\text { count }\end{array}$ & $\begin{array}{l}\text { \% Correct } \\
\text { Facility }\end{array}$ & $\begin{array}{l}\text { SD } \\
\text { Disc. } \\
\text { Index }\end{array}$ & $\begin{array}{l}\text { Disc. } \\
\text { Coeff. }\end{array}$ \\
\hline very much like it & $24 / 57$ & $(42 \%)$ & 57 & 42 & 0 & 0.214 & 0.604 \\
like it & $20 / 57$ & $(35 \%)$ & & & & & \\
ok & $11 / 57$ & $(19 \%)$ & & & & & \\
don't like to use software & $2 / 57$ & $(4 \%)$ & & & & & \\
hate to use software & $0 / 57$ & $(0 \%)$ & & & & & \\
\hline
\end{tabular}


Similar the participants love to use internet for logistics business application, and are very fund of web-enabled on-line applications. Amazingly nobody dislikes the internet, or even hates going online.

Table 3: Like to use internet

\begin{tabular}{llllllll}
\hline Internet & $\begin{array}{l}\text { R. } \\
\text { Counts }\end{array}$ & $\mathbf{R . \%}$ & $\begin{array}{l}\text { Q. } \\
\text { count }\end{array}$ & $\begin{array}{l}\text { \% } \\
\text { Facility }\end{array}$ & $\begin{array}{l}\text { Correct } \\
\text { SD }\end{array}$ & $\begin{array}{l}\text { Disc. } \\
\text { Index }\end{array}$ & $\begin{array}{l}\text { Disc. } \\
\text { Coeff. }\end{array}$ \\
\hline very much like it & $29 / 57$ & $(51 \%)$ & 57 & 51 & 1 & 0.071 & 0.503 \\
like it & $19 / 57$ & $(33 \%)$ & & & & & \\
ok & $8 / 57$ & $(14 \%)$ & & & & & \\
don't like to use software & $0 / 57$ & $(0 \%)$ & & & & & \\
hate to use software & $0 / 57$ & $(0 \%)$ & & & & & \\
\hline
\end{tabular}

E-mail is also very popular, nobody dislikes it but 35\% of the participants are just ok with it, probably because they are aware how time consuming responding to e-mail correspondence in a business setting can be.

Table 4: Like to use e-mail

\begin{tabular}{|c|c|c|c|c|c|c|c|}
\hline e-mail & $\begin{array}{l}\text { R. } \\
\text { Counts }\end{array}$ & R.\% & $\begin{array}{l}Q . \\
\text { count }\end{array}$ & $\begin{array}{l}\% \quad \text { Correct } \\
\text { Facility }\end{array}$ & SD & $\begin{array}{l}\text { Disc. } \\
\text { Index }\end{array}$ & $\begin{array}{l}\text { Disc. } \\
\text { Coeff. }\end{array}$ \\
\hline very much like it & $22 / 57$ & $(39 \%)$ & 57 & 39 & 0 & 0.143 & 0.569 \\
\hline like it & $13 / 57$ & $(23 \%)$ & & & & & \\
\hline ok & $20 / 57$ & $(35 \%)$ & & & & & \\
\hline don't like to use software & $0 / 57$ & $(0 \%)$ & & & & & \\
\hline hate to use software & $0 / 57$ & $(0 \%)$ & & & & & \\
\hline
\end{tabular}

Social media interestingly is not liked by $2 \%$ of the participants, they probably are aware of the risks associated with social media, in particular in a corporate setting, and how much effort is involved in maintaining a social media presence for the corporation including damage control. Almost half the respondents very much like social media, even in business setting. Social media as defined here included facebook as well as services like line and what's up to stay in contact with customers and coworkers, to exchange multi-media messages real-time.

Table 5: Like to use social media

\begin{tabular}{llllllll}
\hline Social Media & $\begin{array}{l}\text { R. } \\
\text { Counts }\end{array}$ & R.\% & $\begin{array}{l}\text { Q. } \\
\text { count }\end{array}$ & $\begin{array}{l}\text { \% Correct } \\
\text { Facility }\end{array}$ & SD & $\begin{array}{l}\text { Disc. } \\
\text { Index }\end{array}$ & $\begin{array}{l}\text { Disc. } \\
\text { Coeff. }\end{array}$ \\
\hline very much like it & $24 / 57$ & $(42 \%)$ & 57 & 42 & 0 & 0.036 & 0.474 \\
like it & $20 / 57$ & $(35 \%)$ & & & & & \\
ok & $12 / 57$ & $(21 \%)$ & & & & & \\
don't like to use software & $1 / 57$ & $(2 \%)$ & & & & & \\
hate to use software & $0 / 57$ & $(0 \%)$ & & & & & \\
\hline
\end{tabular}

The usage of smart phones including i-phones was even more welcomed 63\% very much like to use smart phones and a combined $80 \%$ like them. This clearly shows the move from desk-top computer to mobile computing. Hand-held applications are very much embraced by logistics professionals and continue to grow in popularity.

Table 6: Like to use smart phones

\begin{tabular}{llllllll}
\hline Smart Phone & $\begin{array}{l}\text { R. } \\
\text { Counts }\end{array}$ & $\mathbf{R . \%}$ & $\begin{array}{l}\text { Q. } \\
\text { count }\end{array}$ & $\begin{array}{l}\text { \% } \\
\text { Facility }\end{array}$ & $\begin{array}{l}\text { Correct } \\
\text { SD }\end{array}$ & $\begin{array}{l}\text { Disc. } \\
\text { Index }\end{array}$ & $\begin{array}{l}\text { Disc. } \\
\text { Coeff. }\end{array}$ \\
\hline very much like it & $36 / 57$ & $(63 \%)$ & 57 & 63 & 0 & -0.071 & 0.392 \\
like it & $13 / 57$ & $(23 \%)$ & & & & \\
ok & $8 / 57$ & $(14 \%)$ & & & & \\
don't like to use software & $0 / 57$ & $(0 \%)$ & & & & & \\
hate to use software & $0 / 57$ & $(0 \%)$ & & & & & \\
\hline
\end{tabular}


In terms of user friendliness only $8 \%$ of the participants find the logistics applications not user friendly, the majority considers them very user friendly and user friendly, a possible explanation is that most of the applications offer elaborate GUI (graphical user interfaces).

Table 7: Ease of Use

\begin{tabular}{lllllllll}
\hline User friendliness & $\begin{array}{l}\text { R. } \\
\text { Counts }\end{array}$ & R.\% & $\begin{array}{l}\text { Q. } \\
\text { count }\end{array}$ & $\begin{array}{l}\text { \% } \\
\text { Facility }\end{array}$ & Correct & SD & $\begin{array}{l}\text { Disc. } \\
\text { Index }\end{array}$ & $\begin{array}{l}\text { Disc. } \\
\text { Coeff. }\end{array}$ \\
\hline $\begin{array}{l}\text { very user friendly } \\
\text { user friendly }\end{array}$ & $23 / 61$ & $(38 \%)$ & 61 & 38 & 0 & 0.385 & 0.305 \\
$\begin{array}{l}\text { somewhat user } \\
\text { friendly }\end{array}$ & $14 / 61$ & $(30 \%)$ & & & & & \\
$\begin{array}{l}\text { not user friendly } \\
\text { not at all user } \\
\text { friendly }\end{array}$ & $0 / 61$ & $(23 \%)$ & & & & & \\
\hline
\end{tabular}

Not surprisingly the majority $72 \%$ of the participants prefer COTS commercial of the shelf software over in-house developed software.

Table 8: COTS or in-house solution

\begin{tabular}{lllllllll}
\hline COTS & $\begin{array}{l}\text { R. } \\
\text { Counts }\end{array}$ & R.\% & $\begin{array}{l}\text { Q. } \\
\text { count }\end{array}$ & $\begin{array}{l}\text { \% } \\
\text { Facility }\end{array}$ & Correct & SD & $\begin{array}{l}\text { Disc. } \\
\text { Index }\end{array}$ & $\begin{array}{l}\text { Disc. } \\
\text { Coeff. }\end{array}$ \\
\hline $\begin{array}{l}\text { commercial of the } \\
\text { shelf software }\end{array}$ & $44 / 61$ & $(72 \%)$ & 61 & 72 & 0 & 0.077 & 0.211 \\
$\begin{array}{l}\text { (COTS) } \\
\text { in-house software }\end{array}$ & $17 / 61$ & $(28 \%)$ & & & & & & \\
\hline
\end{tabular}

Discussion: The participants of this study found that the logistics software applications in the majority are very user friendly and offer easy to use interfaces. The participants also preferred webenabled on-line applications. Also a smaller footprint in form of mobile applications is preferred over desk top applications. The way is paved to mobile commerce in the logistics business and the smaller the devices the more will they be used by logistics professionals. It appeared that the English user interfaces were not a handicap in terms of user friendliness and user acceptance. Supply chain management applications (Bozarth \& Handfielf, 2006) as in the literature appear to increase in popularity and become more popular. Amazingly RFID and GPS are well-known household names among students and the applications are gaining in popularity. GPS as it is being used in private cares and RFID as it is getting more and more common place in retail applications. Warehouse management applications were very popular among the students, maybe because the inventory and demand part of logistics is the oldest software application reaching back to the days of accounting software. Students appear to be aware of the risks of social media especially when it comes to corporate setting

\section{Conclusion}

In conclusion there is still a big gap between how information systems are used in the personal lives of Asian students and in business. While embracing i-pad, i-phones and smart phones in general using social applications like facebook, line and what's up, students are less comfortable using these apps for business and return to using the phone or e-mail. The internet is great enabler in terms of information gathering and dissemination, but students have to learn how to make use of them in a business setting and in particular setting of logistics on a national and international level. One other conclusion based on the hypothesis is that the perception of the software changes with your role as developer or user. What the developer finds as easy to use software and self explanatory and user friendly is often perceived as less than user friendly software by the user.

\section{Hypothesis}

- Developer and end users have different perception of user friendly

- Software applications are used in a personal but not in a professional setting

- The development of logistics industry standards are still in its infancy

- Logistics software is more international by its very nature 
- Both MIS and Logistics students have to gain a better understanding of the application and systems being used.

\section{Figure 1: Logistics Software Classifications}

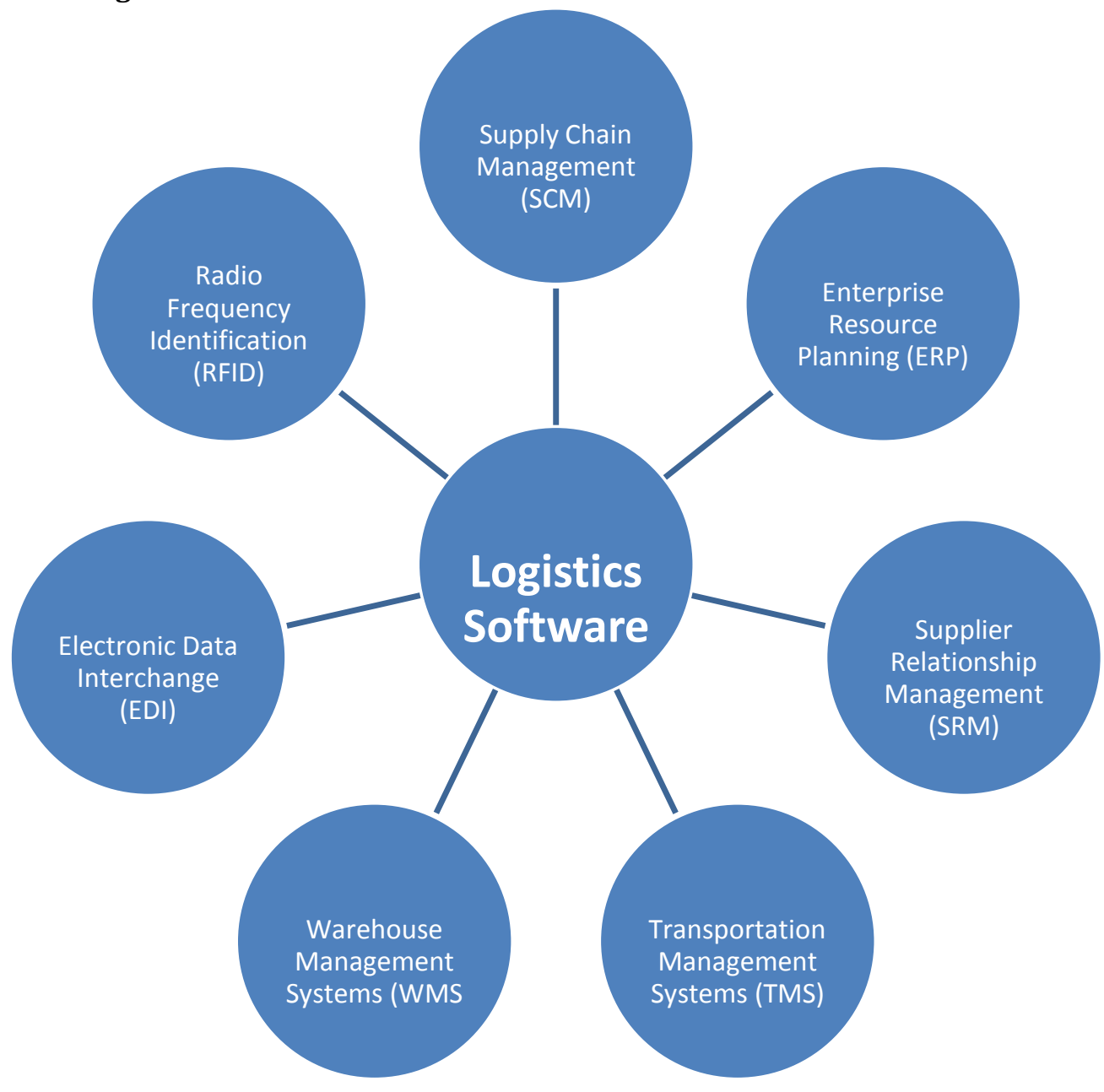

Some applications or features are perceived as useful by the software designer and developer but as useless by the actual logistics user. What is technically feasible maybe too costly for the logistics professional from a time and money stand point.

Recommendations: Logistics software has a long way to come, but made significant strives in the last few years. The development of international standards in terms of IT applications in logistics has made great progress both in hardware and software standards. Software applications in Asia often lack the interfaces and middleware to bridge various applications for in-house, government (customs) and customer usage ending up in re-entering the data in various formats. There is another issue which deals with the creation of the software and middleware and the available skill sets for a reasonable cost. Cost is also a major issue when it comes to the decision to automate a manual process. In Asia and in particular Thailand the labor costs are relatively low compared to the price of international software licenses. Therefore the integration of software applications is driven by the customer requirements, and the customer facing solutions are being computerized and integrated while the internal processes still rely on manual processes and copying and recopying original paperwork and entering into the system and cross checking the outputs from previous systems. The recommendation is to expand the research from logistics software to logistics information systems (LIS) 


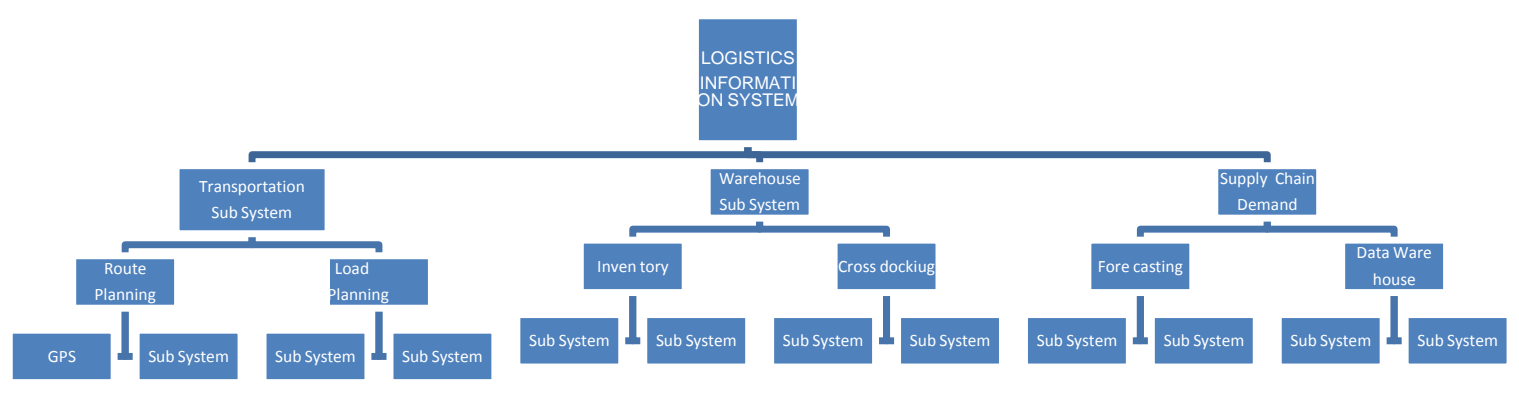

\section{References}

Alavi, M. \& Carlson, P. (1992). A review of MIS research and disciplinary development. Journal of Management Information Systems, 8(4), 45-62

Anderson, D. (2003). Selling Supply Chain Software: Strategies for the New Millenium. ASCET 5.

Arnold, D. (2008). Handbook of Logistics. Springer Verlag, Heidelberg. (In German)

Baumgarten, H. (2001). Logistics in the e-period, FAZ Verlag -Bereich Buch, Frankfurt am Main. (In German)

Bozarth, C. \& Handfielf, R. (2006). Introduction to Operations and Supply Chain Management. Prentice Hall, Upper Saddle River, NJ.

Gammelgaard, B. \& Larson, P. D. (2001). Logistics skills and competences for supply chain management. International Journal of Physical Distribution \& Logistics Management, 22(2), 344-357.

Markus, M. L. \& Robey, D. (1988). Information Technology and Organizational Change: Causal Structure in Theory and Research. Management Science, 34(5), 583-598. 